\title{
A Hierarchical Linear Modeling Approach to Understanding the Role of Eth- nicity and Socioeconomic Status on Precollege Engineering Conceptions Re- search to Practice
}

\section{DeLean Tolbert, Purdue University, West Lafayette}

DeLean Tolbert is an Engineering Education doctoral candidate at Purdue University. She earned a B.Sc. in Electrical Engineering from the University of Michigan-Dearborn and a M.S. in Industrial Engineering from the University of Michigan. Through her dissertation, DeLean investigates the ways that Black boys develop Engineer of 2020 attributes in their precollege out-of-school time lived experiences. This work will serve as a foundation for her future research, through which she anticipates exploring how ethnically diverse students apply these attributes to engineering tasks in both formal and informal settings.

\section{Dr. Kerrie Anna Douglas, Purdue University, West Lafayette}

Dr. Douglas is a Visiting Assistant Professor in the Purdue School of Engineering Education. Her research is focused on methods of assessment and evaluation unique to engineering learning contexts. 


\title{
A Hierarchical Linear Modeling Approach to Understanding the Role of Ethnicity and Socioeconomic Status on Precollege Engineering Conceptions Research to Practice
}

\begin{abstract}
Traditional precollege formal education includes state and federal mandated science and mathematics content. Most recently standards also include engineering content to support initiatives that. prepare more of the American population for the engineering challenges of the future. This study focused on a precollege engineering education intervention. Potential interactions between student and school level factors and students' pre-test achievement were explored using a multilevel modeling data analysis approach (i.e. investigating students within schools). Findings suggest that the statistically significant predictors of the students' pre-test scores are school socioeconomic status and ethnicity. Students who attended a school with a higher proportion of students on free and reduced lunch (FRL) - where FRL is used as a measure of socio-economic status - on average have lower scores than those who attend schools with a lower proportion of FRL receiving students. The second finding is that on average, African American and Hispanic students earn fewer points on the pre-test than do students belonging to other ethnic groups. The findings further suggest that family and community knowledge can influence student knowledge and test scores. As engineering education researchers and practitioners, we must apply these insights to the ways that we engage with diverse students and to the design of our curricula.
\end{abstract}

\section{Introduction}

Engineering education researchers, educators and school districts have increased interest in engineering curriculum specifically developed for elementary students, in part, because of the recent the Next Generation Science (NGSS) Standards. ${ }^{[1]}$ Prior to NGSS, forward thinking educators across the nation had already found ways to engage students in engineering thinking and practice in their classrooms. ${ }^{[2]}$ However, engineering knowledge and practice is not restricted to classroom experiences. Students often have knowledge and perceptions about what engineering is and what engineers do that is informed from their out-of-class experiences. In order to design effective curriculum and pedagogies, we must seek to understand how these conceptions are formed through lived experiences, how they impact student learning, and how they manifest in the lives of children from diverse backgrounds.

Student and community socioeconomic status (SES) can also impact knowledge and learning. Environmental factors, such as family and neighborhood, can positively or negatively influence the academic achievement of students from lower SES communities. Students from higher SES communities are less impacted by these environmental factors. ${ }^{[3]}$ Berliner argues that all too frequently, educational reform fails to consider the impact of SES on the student academic achievement, further perpetuating the layered issues that correlate low SES with lower the academic achievement. ${ }^{[3]}$ SES plays a larger role than many educators and researcher are ready to admit. As engineering educators and researchers, we must not only focus our attention on improving interventions and instruments but we must also critically evaluate the ways that we are addressing issues of poverty and community structure in our curriculum design. Interventions and curricula must not be "one-size-fits all" rather our designs must take into consideration, the condition of the educational system and students that we are aiming to impact. 
We need to understand where learners are coming from when they enter the classroom. What are their experiences and how has that impacted their knowledge? What role does poverty place in their experiences? How does the SES of their community impact learning opportunities and experiences provided to the students? Not all students come into engineering with the same exposure. We must know what our students' conceptions of engineering are and learn their norms and values. This understanding can help inform curricula design that will be aligned with student values and will make a lasting impact on their understanding of engineering and science.

\section{Literature Review}

Dyehouse, Yoon, Lucietto, Diefes-Dux ${ }^{[4]}$ investigated the effects of the teacher development program partnership and the impact on student science and engineering learning. The results affirmed that well designed professional development could have an impact on student knowledge and engineering identity. In order to measure the effects, data included a treatment group and a control group, in which both groups took the pre-posttests at the beginning and end of the school year. These tests were administered by the teachers and then given to the researchers for analysis. Overall, the researchers found that students in the treatment group scored higher than that students in the control group on the knowledge tests and on the engineering career subscale; however, on the identity tests they found no significant difference. The researchers were also specifically examining the effects of group and sex on the post test scores. With respect to sex, the researchers found no significant difference between male and female students on any of the scales.

Other studies have investigated the impact of well-designed professional development on engineering knowledge learning. ${ }^{[5]}$ Practitioners and researchers question if students are able to retain information learned from interventions. Tafur, Douglas, Diefes-Dux ${ }^{[6]}$ observed students for third and fourth grade students for two years and found that they were able to earn the highest test scores and demonstrate retention of the engineering knowledge learned in previous years. Furthermore, some second grade students who were exposed to engineering curriculum, matriculated to third grades classes that did not include engineering curriculum. When tested, these students demonstrated an increase in engineering knowledge. This was evidence that they retained the information taught to them in the second grade.

Douglas, Wiles, Yoon \& Deifes-Dux ${ }^{[7]}$ performed a case study on one school in the data set and interviewed four teachers about their professional development. Specifically, they were asked about their perceived value of teaching engineering in the elementary curriculum, about the support they receive to teach engineering and how they implemented the curriculum. The researchers also analyzed the students' test scores for their respective teachers. Again students in the third and fourth grade had the highest gains in the engineering knowledge tests. Additionally, the teachers saw value in teaching engineering to young students, in areas such as teamwork and social development, in addition to learning engineering concepts.

In a separate study using the same data set, the role of student sex was also explored in relation to pre-post test data on the engineering identity scale. Douglas, Mihalec-Adkins \& Diefes-Dux ${ }^{[8]}$ used MANOVA to analyze differences between boys and girls scores on the engineering identity pre-posttest, at each grade level. With respect to the pre-test data, the researchers expected to 
find a significant difference in engineering career identity by sex. However, the results from their study showed that not only did male and female students perform similarly on the pretest engineering careers identity scale but also both groups significantly improved their scores on the post-test.

Another important factor, is the role of socioeconomic status and its impact on the test-scores in this data set. Douglas, Yoon, Tafur \& Diefes-Dux ${ }^{[9]}$ explored the relationship between a school's socioeconomic status, teacher engineering experience, students gender, students race/ethnicity, and student prior exposure to engineering using path analysis. Key findings relative to this study include:

- Students attending lower socio-economic status schools did not perform as well as students who do not attend lower socioeconomic status schools on the science and engineering posttests, and

- Prior engineering exposure led to significantly higher pre-test scores but did not have a significant difference on posttest scores.

Engineering knowledge in elementary school students is influenced by both internal and external factors. However, external factors have a disproportionate impact on the students from lower socioeconomic status communities. Underrepresented minorities are often overrepresented in these communities. This study addresses the intersection between the projected growth of underrepresented minorities in the United States, the disproportionate representation of minorities in lower SES communities, the role of SES on academic achievement and the need to prepare Americans for future engineering challenges. The purpose of this study is to examine the school and personal factors that are significant to elementary students' understanding prior to classroom experiences with engineering. The following research questions guided this investigation:

- When factoring in SES, how does that change our understanding of the ways we teach engineering to elementary students?

- What is the impact of SES on elementary students learning engineering?

- Do school characteristics, student ethnicity, and the sex of the student help explain student scores on the 15 -item Engineering Knowledge Test given to $2^{\text {nd }}$ $4^{\text {th }}$ graders?

\section{Methods}

\section{Research Design}

Given the stated purpose of this study, the data were analyzed using multilevel modeling. In social science research, multilevel modeling is a preferred method when data is nested in different levels (i.e. children in families, teachers in schools, schools) neighborhoods. Multilevel modeling was selected for this study because other statistical analysis methods do not take into account the independence between the measured data and the levels. Hence, increasing the difficulty of measuring each levels effects on the outcome under investigation. The multilevel analysis (HLM) is briefly described in the analysis section. 


\section{Setting and Sampling}

The data collected for this study was part of a larger NSF funded project for Purdue's INSPIRE to collaborate with a large school district to southwestern United States to bring teacher professional development for elementary teachers to bring engineering into their classroom. The program is more fully described in Yoon, Diefes-Dux, \& Strobel. ${ }^{[5]}$ This sample includes information about the school, class and students. However, socioeconomic status of each student (beyond race, sex and teacher) is not available and therefore, this was approximated at the school level. The school socioeconomic status was determined using the proportion of students on free and reduced lunch. We investigated potential relationships between the schools approximated SES and the achievement of the students at that school. This study includes three elementary $2^{\text {nd }}-4^{\text {th }}$ grade levels. Students were selected to participate in the original study by proxy. The participating school district and participating teachers determined which students participated in this study.

After deleting missing data at the student and school levels, our analysis sample included 975 ethnically, socioeconomically diverse students from nine schools. All the students' pretest scores for the third year of the study were considered, although by the third year of investigation some of the 3rd and 4th grade students may have been exposed to the intervention. The district demographics include: Hispanic, African American, White, Native American students and socioeconomic status. The analysis sample is made up of 497 boys (51\%) and 478 girls (49\%).

\section{Instrument - The Student Knowledge Test (SKT)}

The Student Knowledge Test (SKT), was designed to measure science and engineering knowledge. ${ }^{[10]}$ The SKTs, measure science, engineering and technology concepts, with 15 multiple choice items for each topic area. Each grade had a different version of the instrument and the instrument was modified each year during the study. The instrument includes engineering, science and technology questions. The engineering content was aligned with Engineering is Elementary units, which would be taught to the students between the facilitation of the pre-posttests. The Engineering Identity subscale ${ }^{[10]}$ measured the engineering identity development and contained two subscales (academic and engineering career). The academic subscale measures students' knowledge about the types of work that engineers do and the engineering career subscale measures engineering career aspirations. This instrument was developed and revised in 2008 and 2009, respectively. The SKT was used as a pre- and post-test. The pre-test instrument, which is the focus of this paper, was used as a measure to get an idea of student engineering knowledge prior to learning the content for the year. This data will be used to explore student conceptions of engineering, science, and technology. Furthermore, potential interactions between students' pretest scores and school SES, student-teacher ratio, student ethnicity, and sex will be discussed in the results section. 
Table 1: Descriptive statistics of predictors and outcomes

\begin{tabular}{|c|c|c|c|}
\hline & Mean & Std. Deviation & N \\
\hline Score & 4.925 & 2.4893 & 975 \\
Prop_FRL & .5360 & .31699 & 975 \\
Ethnicity & 3.66 & 1.371 & 975 \\
Sex & .51 & .500 & 975 \\
AVESCORE & 4.9251 & .93300 & 975 \\
\hline
\end{tabular}

Data Analysis

Multilevel analysis is a statistical analysis tool that looks at the relationships between and among groups. In this study it was used because of the structure of the data; there are students (level 1) in specific schools (level 2). Using HLM multilevel analysis we can identify the predictive ability of level 1 (personal, student) and level 2 (school level) factors on students incoming knowledge about engineering. Other researchers might consider MANOVA as an appropriate analytical approach for the data we have described. For example, MANOVA can test for differences in means of multiple groups (i.e. knowledge test score differences between male, female students, and $2^{\text {nd }}$ grade students from school A). However, multilevel modeling (HLM) is a superior approach to MANOVA because it helps to investigate unidentified models and the independence between the school and student level data.

\section{Control Variables}

The independent variables of this study include both student level and school level predictive variables. Analyses included two student level control variables: ethnicity: (Other, Native/Alaskan, Asian/Pacific Islander, African American, Hispanic, White, Multiracial) and sex: male and female. At the student level the predictive ability of race and sex on students' achievement on the pre-test were measured. Data at the school level included the estimate SES of the school, which was informed by the school zip code and proportion of students on free or reduced lunch. This is the ratio of students on Free or Reduced lunch to the total enrollment of all students at the respective school. At the school level, the predictive ability of each school's proportion of students on free and reduced lunch (FRL) on each individual student's pretest score was measured.

\section{The Dependent Variable}

The dependent variable is the overall score earned on the SKT pretest. The students were given one point for each correct answer on the pre-test. A total of 15 points were possible.

\section{Results}

Model descriptions

The analysis began by fitting the data to a random-effects ANOVA to determine if there was statistically significant variance in the means. This analysis led us to continue with HLM analyses empty model was created, it could be used as a baseline comparison to compare the predictive ability of more complex models. Then the predictors at both level 1 and level 2 were investigated to determine if there was any within or between group variations. 
The first model was the null model. All random effects are fixed and this is equivalent to the one-way ANOVA.

$$
\begin{gathered}
S C O R E_{i j}=\gamma_{00}+r_{i j} \\
\sigma^{2}=6.20214
\end{gathered}
$$

Table 2. Final estimation of fixed effects:

\begin{tabular}{lrrrrr}
\hline Fixed Effect & Coefficient & $\begin{array}{r}\text { Standard } \\
\text { error }\end{array}$ & $t$-ratio & $\begin{array}{r}\text { Approx. } \\
\text { d.f. }\end{array}$ & $p$-value \\
\hline $\begin{array}{l}\text { For INTRCPT1, } \beta_{0} \\
\text { INTRCPT2, } \gamma_{00}\end{array}$ & 4.926078 & 0.079798 & 61.732 & 973 & $<0.001$ \\
\hline
\end{tabular}

The second model is the ANOVA Model (null model with the residual term in the level-2). This inclusion of the residual term allows for random intercepts for each school and it included because at this point we have not proven that each school's SES has the same predictive ability for all students. This is the random effects model.

$$
\begin{gathered}
\operatorname{SCORE}_{i j}=\gamma_{00}+u_{0 j}+r_{i j} \\
\sigma^{2}=5.40323
\end{gathered}
$$

Table 3. Final estimation of fixed effects:

\begin{tabular}{lrrrrr}
\hline Fixed Effect & Coefficient & $\begin{array}{r}\text { Standard } \\
\text { error }\end{array}$ & $t$-ratio & $\begin{array}{r}\text { Approx. } \\
\text { d.f. }\end{array}$ & $p$-value \\
\hline $\begin{array}{c}\text { For INTRCPT1, } \beta_{0} \\
\text { INTRCPT2, } \gamma_{00}\end{array}$ & 4.727106 & 0.282357 & 16.742 & 13 & $<0.001$ \\
\hline
\end{tabular}

Table 4. Final estimation of variance components

\begin{tabular}{rrrccc}
\hline Random Effect & $\begin{array}{r}\text { Standard } \\
\text { Deviation }\end{array}$ & $\begin{array}{r}\text { Variance } \\
\text { Component }\end{array}$ & d.f. & $\chi^{2}$ & $p$-value \\
\hline INTRCPT1, $u_{0}$ & 0.94613 & 0.89515 & 13 & 163.89329 & $<0.001$ \\
level-1, $r$ & 2.32448 & 5.40323 & & & \\
\hline
\end{tabular}

Given that the second model was selected, the null hypothesis for this portion of the investigation was that the ability of the student on average is the same for all schools.

$$
H_{0}: \tau^{2}=0 \text { (i.e., if } H_{0} \text { is true, all } U_{j} \text { are equal.) }
$$

If this hypothesis was true, then the student's performance is not dependent on the school that they attend. However, after testing the null model, it was determined that school performance was not the same across all school and the hypothesis was rejected $\left(. \hat{\tau}^{2}=.89515 S D=.946\right.$ $\chi 2(13)=163.893 \mathrm{p}<0.001$ reliability estimate $=.802 \mathrm{Rho}=.142)$. Based on the analysis above, there is sufficient variance across the schools to conduct further HLM analysis.

The next step in the analysis was to look at the level 1 or level 2 predictors and see if there is improvement in how well the model predicts the outcome variable (SCORE $\left.E_{i j}\right)$. A correlation analysis between plausible predictors and the student's score was used to identify which variables would best explain the variance in the score for the individual students and the schools. This 
helped to determine how to proceed with the investigation. According to the correlation analysis, we were able to determine which variables might help explain variance in the student scores (Score) and the average knowledge score for each school (AVESCORE). At the school level, the proportion of students receiving free and reduced lunch $(-0.8, p=0.000, p<0.01)$ and ethnicity $(0.169, \mathrm{p}=0.000, \mathrm{p}<0.01)$ had statistical significant correlation with the average score of each school. At the student level, both sex and ethnicity were tested for correlation. Only ethnicity had statistically significant $(0.094, \mathrm{p}=0.002, \mathrm{p}<0.01)$ correlations with the score earned by each student.

The next phase in the investigation was to use the predictors (PROP_FRL and ETHNICITY) to run the slopes model with intercepts. First, the level 2 predictor, PROP_FRL was investigated to attempt to explain the variance in the students' response which was evident in the analysis of the null model (i.e. empty model with no predictors). By including the school level predictor in the model, the following question was investigated: "What is the impact a school's proportion of students on free and reduced lunch on the school's average knowledge score?" The null hypothesis is that the knowledge test achievement is not related to the proportion of students on free and reduced lunch at a given school $(=0)$. The results led us to reject the null hypothesis $\left(\left(. \hat{\tau}^{2} .42185, \mathrm{SD}=0.650, \chi 2(11)=65.49316 \mathrm{p}<0.001\right)\right.$ and conclude that there is evidence that the knowledge test achievement could partially be explained by the school SES.

$$
\sigma^{2}=5.40193
$$

$\tau$ INTRCPT $1, \beta_{0} 0.42185$

Table 5. Final estimation of fixed effects:

\begin{tabular}{lccccc}
\hline Fixed Effect & Coefficient & $\begin{array}{r}\text { Standard } \\
\text { error }\end{array}$ & $t$-ratio & $\begin{array}{r}\text { Approx. } \\
\text { d.f. }\end{array}$ & $p$-value \\
\hline For INTRCPT1, $\beta_{0}$ & & & & & \\
INTRCPT2, $\gamma_{00}$ & 8.342207 & 4.214077 & 1.980 & 11 & 0.073 \\
STU_TRAT, $\gamma_{01}$ & -0.130318 & 0.232283 & -0.561 & 11 & 0.586 \\
RAW_PROP, $\gamma_{02}$ & -2.747692 & 0.929902 & -2.955 & 11 & 0.013 \\
\hline
\end{tabular}

Table 6. Final estimation of variance components:

\begin{tabular}{rrrrrr}
\hline Random Effect & $\begin{array}{r}\text { Standard } \\
\text { Deviation }\end{array}$ & $\begin{array}{r}\text { Variance } \\
\text { Component }\end{array}$ & $d . f$. & $\chi^{2}$ & $p$-value \\
\hline INTRCPT1, $u_{0}$ & 0.64950 & 0.42185 & 11 & 65.49316 & $<0.001$ \\
level-1, $r$ & 2.32421 & 5.40193 & & & \\
\hline
\end{tabular}

The results indicate that the school SES and ethnicity predictors help to in explain a student's pretest score. As a reminder, in study, the proportion of students on FRL to operationalize the 
school SES. So the findings in this study suggest that the SES of a school helps explain an individual student's pretest score and can also help explain that schools average score. In other words, students who attend schools with more students on free and reduced lunch typically earn lower scores on the pre-test. This suggests that these students have less knowledge of engineering, science and technology careers and concepts at the time the pretest was taken than their peers.

Based on findings from this HLM analysis, a student's ethnicity also provided some explanation for the variance in the scores on the knowledge test. A post hoc- one-way ANOVA between the different ethnic group was completed and it confirmed that there was a statistically significant difference between the group mean scores. The null hypothesis for this analysis is that mean scores of each ethnicity are equal. However, this hypothesis is rejected $\left(\mathrm{F}_{(6,967)}=12.027, \mathrm{p}=\right.$ $0.000, \alpha=.05)$. The difference between each ethnic groups average scores was statistically significant.

Table 7. Descriptives by for dependent variable Score

\begin{tabular}{|c|c|c|c|c|c|c|c|c|}
\hline & \multirow[b]{2}{*}{$\mathrm{N}$} & \multirow[b]{2}{*}{ Mean } & \multirow[b]{2}{*}{$\begin{array}{c}\text { Std. } \\
\text { Deviation }\end{array}$} & \multirow[b]{2}{*}{$\begin{array}{l}\text { Std. } \\
\text { Error }\end{array}$} & \multicolumn{2}{|c|}{$\begin{array}{l}\text { 95\% Confidence Interval } \\
\text { for Mean }\end{array}$} & \multirow[b]{2}{*}{ Minimum } & \multirow[b]{2}{*}{ Maximum } \\
\hline & & & & & $\begin{array}{l}\text { Lower } \\
\text { Bound }\end{array}$ & $\begin{array}{l}\text { Upper } \\
\text { Bound }\end{array}$ & & \\
\hline Other & 73 & 4.137 & 2.3113 & .2705 & 3.598 & 4.676 & .0 & 10.0 \\
\hline Native/Alaskan & 6 & 4.667 & 1.7512 & .7149 & 2.829 & 6.504 & 2.0 & 7.0 \\
\hline $\begin{array}{l}\text { Asian/Pacific } \\
\text { Islander }\end{array}$ & 70 & 6.014 & 2.5735 & .3076 & 5.401 & 6.628 & 1.0 & 12.0 \\
\hline $\begin{array}{l}\text { African } \\
\text { American }\end{array}$ & 161 & 4.814 & 2.3511 & .1853 & 4.448 & 5.180 & .0 & 13.0 \\
\hline Hispanic & 388 & 4.381 & 2.3370 & .1186 & 4.148 & 4.615 & .0 & 13.0 \\
\hline White & 274 & 5.712 & 2.5392 & .1534 & 5.410 & 6.014 & .0 & 13.0 \\
\hline Multiracial & 2 & 3.500 & .7071 & .5000 & -2.853 & 9.853 & 3.0 & 4.0 \\
\hline Total & 974 & 4.926 & 2.4904 & .0798 & 4.769 & 5.083 & .0 & 13.0 \\
\hline
\end{tabular}

ANOVA

\begin{tabular}{|l|r|r|r|r|r|}
\hline & Sum of Squares & \multicolumn{1}{c|}{ df } & Mean Square & \multicolumn{1}{c|}{ F } & Sig. \\
\hline Between Groups & 419.049 & 6 & 69.842 & 12.027 & .000 \\
Within Groups & 5615.628 & 967 & 5.807 & & \\
Total & 6034.678 & 973 & & & \\
\hline
\end{tabular}

To identify how groups were different from each other, a Turkey Post-hoc test compared the knowledge test scores across the six ethnicity categories (Other, Native/Alaskan, Asian/Pacific Islander, African American, Hispanic, White, and Multiracial). The more conservation LSD Post-hoc test was performed on the ethnicity data because of the nature of multiple t-testing and 
the increased threat of committing a type 1 error. The results of the Turkey Post-hoc test demonstrated that some groups differed significantly at $\mathrm{p}<.05$ (see table 8 ).

A Tukey post-hoc test revealed that the time to complete the differences in the means were of Asian/Pacific Islander student scores were statistically significantly higher than the other ethnic groups. On the other hand, the group labeled other scored statistically significantly lower, however, because we do not know the ethnicity of these students it size makes it difficult to make inferences about the group. African American/black students scored statistically significantly lower than White students as did Hispanic students. Furthermore, the mean score of Hispanic students was also statistically significantly lower than African American/Black students.

Table 8: Multiple Comparisons Test Results

\begin{tabular}{|c|c|c|c|c|c|c|c|}
\hline \multicolumn{8}{|c|}{ Multiple Comparisons } \\
\hline $\mathrm{J}$ & Other & $\begin{array}{l}\text { Native/Alask } \\
\text { an }\end{array}$ & $\begin{array}{c}\text { Asian/Pacifi } \\
\text { c Islander }\end{array}$ & $\begin{array}{c}\text { African } \\
\text { American }\end{array}$ & Hispanic & White & Multiracial \\
\hline Other & --- & -0.5297 & $-1.8773^{*}$ & $-.6767^{*}$ & -0.2445 & $-1.5747^{*}$ & 0.637 \\
\hline Native/Alaskan & 0.5297 & --- & -1.3476 & -0.147 & 0.2852 & -1.045 & 1.1667 \\
\hline $\begin{array}{l}\text { Asian/Pacific } \\
\text { Islander }\end{array}$ & $1.8773^{*}$ & 1.3476 & --- & $1.2006^{*}$ & $1.6328^{*}$ & 0.3026 & 2.5143 \\
\hline $\begin{array}{c}\text { African } \\
\text { American }\end{array}$ & $.6767^{*}$ & 0.147 & $-1.2006^{*}$ & --- & 0.4322 & $-.8980^{*}$ & 1.3137 \\
\hline Hispanic & 0.2445 & -0.2852 & $-1.6328^{*}$ & -0.4322 & --- & $-1.3302^{*}$ & 0.8814 \\
\hline White & $1.5747^{*}$ & 1.045 & -0.3026 & $.8980^{*}$ & $1.3302^{*}$ & --- & 2.2117 \\
\hline Multiracial & 0.637 & -1.1667 & -2.5143 & -1.3137 & -0.8814 & -2.2117 & --- \\
\hline
\end{tabular}

\section{Discussion}

The lower scores could be due to multiple issues both personal and societal. Female students did not score significantly different than their male peers. This was an expected finding, given that previous studies did not find a significant difference when accounting for sex. We found two interesting results: students who attend a school with more students on free and reduced lunch, on average have lower scores than those who attend schools with fewer free and reduced lunch receiving students and on average, African American and Hispanic students earn fewer points on the pretest than do students belonging to other ethnic groups.

Even when the same resources are provided to all schools, there are still differences within the school among ethnic groups. This finding suggests that may be an advantage to having community knowledge, exposure and resources. For example, the concepts tested on the pretest will be more easily answered correctly, by someone who belongs to a community where there is more access to scientists and engineers (or scientific and engineering knowledge). There is 
unrecognized privilege to being a White (majority) student, which allows these students to (on average) earn more points on even a pre-test. Specifically, because this is a pretest, from these findings we can infer that students from lower SES and racially diverse schools have less informal (outside of school) exposure to engineering. This study also suggests, that family knowledge has a huge bearing on the types of knowledge that the students have. What is concerning is that family and community knowledge (or lack of family and community knowledge) can also influence scores. While family knowledge can positively impact some students, lack of familial knowledge and community knowledge (awareness) related to engineering can negatively impact student achievement.

We as engineering educators and engineering education researchers must be aware of the additional barriers that are faced by African Americans, Hispanics and students in low socioeconomic status communities. These minority and low socioeconomic status communities do not have a level foundation of what engineering is compared to the dominant culture students. These barriers are not simply overcome by exposing them to the same resources as their white counterparts. As this study suggests, there must be other confounding factors that must be accounted for. Future research should investigate the extent to which minority and low socioeconomic students achieve the learning outcomes associated with engineering curriculum, in comparison to their peers who have had more learning opportunities. A truly robust engineering curriculum would seek to address the learning needs of students who have had limited engineering exposure and scaffold all students to achieve equally well across student subgroups.

It is important for us to understand that exposure to engineering concepts and knowledge is good but for specific groups of people, that equality of resources is not enough. The burden is on the researcher to determine the confounding factors exist which negatively impact student achievement in engineering and how to we help students overcome them.

\section{Study Limitations}

The investigation discussed in this publication has some limitations. Quantitative approaches reveal treads within the students' test scores as it relates to groups of similar students, and school and student level factors. However, a qualitative investigation would help further explore the students' experiences. Specifically, interviews would allow further probing into the types of engineering knowledge available in different communities. This could help substantiate our claims. With respect to analyzing specific pre-test questions, future work might include an item analysis to examine student responses. The sole focus on pre-test scores prevented an investigation on the curriculums ability to overcome or address the negative impacts of students and school level factors.

\section{Acknowledgement}

This work was made possible by a grant from the National Science Foundation DLR 0822261. Any opinions, findings, and conclusions or recommendations expressed in this material are those of the authors and do not necessarily reflect the views of the National Science Foundation. We also acknowledge Dr. Yukiko Maeda, Dr. Monica Cardella, and Dr. Heidi Diefes-Dux for their support of this publication and insights provided as we explored the data. 


\section{References}

[1] States, N.L., Next Generation Science Standards : for states, by states, Washington, D.C.: Washington, D.C. : National Academies Press, 2013.

[2] Rodriguez, A.J.," What about a dimension of engagement, equity, and diversity practices? A critique of the next generation science standards.(Report)", Vol. 52, No. 7, 2015, pp. 1031

[3] Berliner, D.C.," Our Impoverished View of Educational Research", Teachers College Record Vol. 108, No. 6, 2006, pp. 949-995.

[4] Yoon, S.Y., M. Dyehouse, A.M. Lucietto, .A. Diefes-Dux, and B.M. Capobianco," The Effects of Integrated Science, Technology, and Engineering Education on Elementary Students' Knowledge and Identity Development", School Science and Mathematics Vol. 114, No. 8, 2014, pp. 380-391.

[5] Yoon, S.Y., H. Diefes-Dux, and J. Strobel," First- Year Effects of an Engineering Professional Development Program on Elementary Teachers", American Journal of Engineering Education Vol. 4, No. 1, 2013, pp. 67-84

[6] Tafur, M., Douglas, K. A., \& Diefes-Dux, H. A., "Changes in Elementary Students' Engineering Knowledge Over Two Years of Integrated Science Instruction (Research to Practice)", American Society for Engineering Education Annual Conference and Exposition, Indianapolis, IN, 2014.

[7] KA Douglas, D.W., SY Yoon, A Diefes-Dux, Heidi, "Elementary teachers' two-year implementation of engineering: A case of success", American Society for Engineering Education, 2013.

[8] Douglas, K.A., \& Mihalec-Adkins, B. P., \& Diefes-Dux, H. A., "Boys and Girls Engineering Identity Development in Early Elementary", 2014 ASEE Annual Conference, 2014.

[9] Douglas, K.A., and So Yoon Yoon, "Factors Influential to Fourth Graders Engineering Learning and Identity Development", American Society of Engineering Education, 2015.

[10] Dyehouse, M., \& Diefes-Dux, H. A., \& Capobianco, B., "Measuring the Effects of Integrating Engineering into the Elementary School Curriculum on Students' Science and Engineering Design Content Knowledge", 2011 Annual Conference \& Exposition, Vancouver, BC, 2011. 